\title{
On-chip mass spectrometric analysis in non-polar solvents by liquid beam infrared matrix-assisted laser dispersion/ionization
}

\author{
Raphael D. Urban ${ }^{1} \cdot$ Tillmann G. Fischer $^{2} \cdot$ Ales Charvat $^{3} \cdot$ Konstantin Wink $^{1} \cdot$ Benjamin $\mathrm{Krafft}^{1} \cdot$ Stefan Ohla $^{1}$.

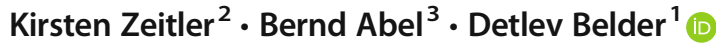

Received: 18 September 2020 / Revised: 1 December 2020 / Accepted: 7 December 2020 / Published online: 21 January 2021

(C) The Author(s) 2021

\begin{abstract}
By the on-chip integration of a droplet generator in front of an emitter tip, droplets of non-polar solvents are generated in a free jet of an aqueous matrix. When an IR laser irradiates this free liquid jet consisting of water as the continuous phase and the non-polar solvent as the dispersed droplet phase, the solutes in the droplets are ionized. This ionization at atmospheric pressure enables the mass spectrometric analysis of non-polar compounds with the aid of a surrounding aqueous matrix that absorbs IR light. This works both for non-polar solvents such as $n$-heptane and for water non-miscible solvents like chloroform. In a proof of concept study, this approach is applied to monitor a photooxidation of $N$-phenyl-1,2,3,4-tetrahydroisoquinoline.
\end{abstract}

Keywords Microfluidics $\cdot$ IR-MALDI $\cdot$ Non-polar solvents $\cdot$ Reaction monitoring

\section{Introduction}

There has been significant progress in coupling microfluidic chips with mass spectrometry (MS) [1-4]. This technique allows to study microfluidic processes on a chip with unsurpassed information content. The most widely applied technology for chip MS hyphenation is based on electrospray ionization (ESI). ESI can be seamlessly integrated on microfluidic devices by the incorporation of an emitter tip. This chip-ESI/ MS technology has been widely applied for coupling various microfluidic applications and corresponding devices to mass spectrometry such as chip electrophoresis [5-7], chip chromatography [8-10], microfluidic reaction devices [11-14], droplet microfluidics [12, 15-19], digital microfluidics [20-22], and paper-based devices [23-26]. Most of these chip applications use water or aqueous mixtures with acetonitrile or methanol as the liquid phase. This fact is beneficial for electrospray

Detlev Belder

belder@uni-leipzig.de

1 Institut für Analytische Chemie, Leipzig University, Linnéstraße 3, 04103 Leipzig, Germany

2 Institut für Organische Chemie, Leipzig University, Johannisallee 29, 04103 Leipzig, Germany

3 Leibniz-Institut für Oberflächenmodifizierung e.V., Abteilung Funktionale Oberflächen, Permoserstr. 15, 04318 Leipzig, Germany ionization, which indeed performs best upon using aqueous mixtures of polar solvents. On the other hand, it is challenging to analyze compounds in non-polar solvents by ESI MS.

To overcome this limited application range, ESI has been the subject of intensive research [27]. Approaches described in the literature include atmospheric pressure chemical ionization (APCI) [28-31], atmospheric pressure photoionization (APPI), solvent-assisted electrospray ionization (SAESI) [32-35], desorption electrospray ionization (DESI) [36-38], easy ambient spray ionization (EASI) [39-43], laser ablation electrospray ionization (LAESI) [44], and low-temperature plasma ionization (LTP) [45]. There are practically no literature reports on direct mass spectrometric on-chip analysis of compounds dissolved in water non-miscible, non-polar solvents. The analysis of compounds in non-polar solvents would in principle be feasible using offline approaches such as MALDI-MS [46-49], but this would require additional offchip steps and would impede real-time analysis. A technology that would allow for on-chip mass spectrometric analyses in non-polar solvents is a missing part in the lab-on-a-chip toolbox with broad applicability, e.g., in micro reaction technology.

We have recently shown that liquid beam desorption mass spectrometry is an exciting alternative to electrospray ionization for microfluidic chips coupling with mass spectrometry [50]. In this approach, a free-standing liquid jet emerging directly from an integrated chip emitter tip is irradiated with an 
IR laser, promoting desorption and ionization of dissolved analytes. This mass spectrometric technique called laserinduced liquid beam ionization/desorption mass spectrometry (LILBID-MS) [51] or infrared matrix-assisted laser dispersion/ionization MS (IR-MALDI-MS) [52, 53] allows to desorb and ionize compounds in liquid beams using solvents containing hydroxy groups [54-57]. Compared to ESI, IR-MALDI has higher tolerance towards salts and additives and is even softer towards "big analytes" like biomolecules [58]. IR-MALDI is mainly applied to analyze compounds in aqueous media, as the method utilizes water or alcoholic solvents as an absorbing matrix. The absorption of infrared light due to the $\mathrm{OH}$ stretch vibration of the aqueous or alcoholic medium is a prerequisite to promote the crucial generation of gas-phase ions of dissolved analytes [59-64]. While this works well for polar compounds, e.g., for biochemical applications, it severely restricts the application scope in synthetic organic chemistry where non-polar solvents are widely used. So even though liquid beam IR-MALDI is an interesting alternative to ESI for chip/MS coupling, it is subject to similar restrictions concerning applied solvents.

Herein, we report the feasibility of performing chip IRMALDI with liquid jets to analyze compounds dissolved in non-polar and water non-miscible organic solvents. Since one of the main applications of this technology is seen in the field of flow chemistry and reaction monitoring, it was exemplarily used to study the photochemical synthesis of an iminium ion from $N$-phenyl-1,2,3,4-tetrahydroisoquinoline in chloroform.

\section{Experimental}

\section{Materials and methods}

Instrumentation The solvents were delivered by an HPLC piston pump (Merck Hitachi L6200, Merck KGaA, Darmstadt, HE, DEU), a NEMESYS high-pressure pump, and/or two NEMESYS low-pressure syringe pumps (CETONI GmbH, Korbußen, TH, DEU) equipped with two $100-\mu \mathrm{L}$ glass syringes (Hamilton Bonaduz AG, Bonaduz, $\mathrm{GR}, \mathrm{CHE})$. The syringes and the microchip were interconnected by fused silica capillaries (360 $\mu \mathrm{m}$ outer diameter (OD), $75 \mu \mathrm{m}$ inner diameter (ID); CS-Chromatographie Service $\mathrm{GmbH}$, Langerwehe, NW, DEU), the chip (Fig. 1) was fluidically connected to peripherals via capillaries using steel connection clamps [65].

For precise positioning, the commercial ESI interface of the MS was replaced by an in-house built positioning table with a precision manipulator (OWIS GmbH, Staufen i.Br., BW, DEU). The laser source (Opolette IR 2731, OPOTEK, Carlsbad, CA, USA) was operated at the following settings: wavelength: $2940 \mathrm{~nm}$; frequency: $20 \mathrm{~Hz} ; 3 \mathrm{~mJ}$ pulse energy. The chip emitter was positioned at a distance of $2 \mathrm{~mm}$ in front

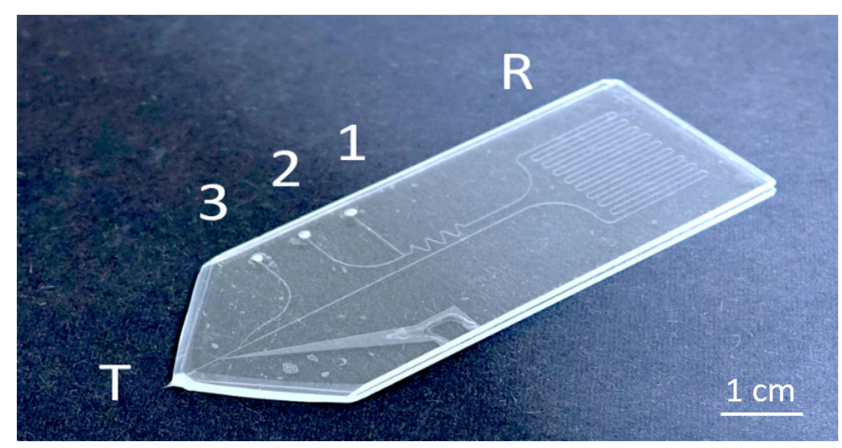

Fig. 1 Image of the used microfluidic chip with inlets 1, 2, and 3. R indicates the reactor region and $\mathrm{T}$ the emitter tip of the chip

and $1 \mathrm{~mm}$ above the MS orifice. The chip was aligned so that the liquid beam, MS ion path, and laser beam were on an imaginary orthogonal 3-D coordinate system. The $15-\mathrm{cm}-$ long optical pathway of the laser beam consisted of $\mathrm{Ag}$ coated mirrors (PF10-03-P01) and a $\mathrm{CaF}_{2}$ plano-convex lens ( $f=7.5 \mathrm{~cm}$; Edmund Optics, Barrington, NJ, USA) with a spot size of $0.28 \mathrm{~mm}^{2}$. The MS (1100 Series, LC/MSD Trap, Agilent Technologies Inc., City of Santa Clara, CA, USA) was used in ion current control (ICC) active mode, with $4 \mathrm{~L} /$ min drying gas, $300{ }^{\circ} \mathrm{C}$ gas temperature, $m / z$ 100-500 mass range, ion dwell time in the trap: variable from 5 to $100 \mathrm{~ms}$, and spray shield voltage of $0 \mathrm{~V}$.

In order to produce stroboscopic images, the liquid jet was positioned between a light-emitting diode (LED) (KINGSO $5 \mathrm{~mm}$, white) and a self-designed mobile microscope (Thorlabs Inc., Newton, NJ, USA), already described in a previous publication, with a camera connected to it (FLIR Flea 3, FL3-U3-20e4M-C, FLIR Systems, Inc., OR, USA) [8]. The laser beam was aligned orthogonally to the liquid jet. The timing was accomplished as follows: The laser triggered a pulse generator (Stanford Research System DG535, Stanford Research Systems, CA, USA), which, after an adjustable delay, sent a TTL voltage pulse $(1 \mu \mathrm{s})$ to the LED and camera (see Supplementary Information (ESM) Figs. S4 to S8, pages 6-9). For images without laser bombardment, the timing was set directly by the pulse generator. A description of the stroboscope setup can be found in the ESM, page 6 .

Microchip design and fabrication The microfluidic glass chips, depicted in Fig. 1, were designed and fabricated in-house by standard photolithography, wet etching, and thermal bonding methods [66]. A detailed description is found in the ESM, page 3. Briefly, the chip consisted of two layers. Both layers were manufactured out of microscope slides of soda lime glass with a size of $76 \mathrm{~mm} \times 26 \mathrm{~mm}$ (Carl Roth $\mathrm{GmbH}+\mathrm{Co}$. KG, Karlsruhe, BW, DEU). The bottom glass layer contained etched channels with a height of $20 \mu \mathrm{m}$ and a diameter of $80 \mu \mathrm{m}$. To close the channels, the slide was thermally bonded to a top layer with powder blasted holes that serve as inlets for pressure-tight fluid delivery. The microchip had the following functional 
units, as shown in Fig. 2: Two interconnected inlet channels, a meandering region that improves the mixing of liquids, and a third make-up inlet that allows the introduction of water as matrix and make-up flow. An image of the setup is provided in the ESM, Fig. S1, page 4. Flow rates from liquids through inlet $1 \mathrm{~s}$ and 2 and the make-up inlet will be addressed as $u_{1}, u_{2}$, and $u_{3}$ respectively. The reactor's total length from the intersection of the two channels and the make-up flow channel was $327 \mathrm{~mm}$. The reactor had an internal volume of $\sim 520 \mathrm{~nL}$ (ESM, Fig. S2, page 4). The outlet of the chip was equipped with an integrated monolithic emitter that narrows the inner diameter of the channel down to $20 \mu \mathrm{m}$ (ESM, Fig. S3, page 5), which enables the generation of a liquid beam at lower flow rates [67]. A pyramidal-shaped emitter tip was manufactured using a grinding machine. Then, a small conical rod of borosilicate glass was fused to the tip by heat provided by an electrified wire coil of constantan. Afterward, the fused glass joint was heated again, and the emitter tip was pulled out by the gravity of the conical borosilicate glass. The exit of the channel was opened by grinding with superfine microgrit (ISO P2500). The inner diameter of the emitter was approximately $20 \mu \mathrm{m}$, and a liquid beam could be established at a flow rate of $80 \mu \mathrm{L} / \mathrm{min}$ water. Unless otherwise specified, the make-up flow was always operated at a flow rate of $120 \mu \mathrm{L} / \mathrm{min}$. Since the samples form a co-flow or droplets with the water matrix after the reactormake-up flow channel junction, the sample concentration is always indicated so that it corresponds to the concentration in the reactor channel. Photochemical reactions were irradiated

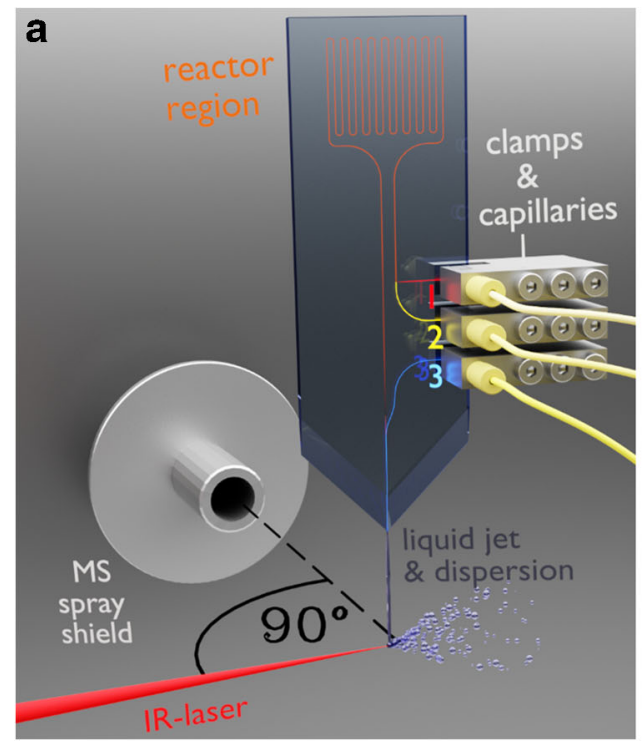

Fig. 2 a Schematic drawing of the microchip liquid beam desorption mass spectrometry system. A liquid jet is generated at the microchip emitter and irradiated with a pulsed IR laser beam, thereby dispersing the liquid. Analyte solutions are introduced into the channels at inlets 1 (red) and 2 (yellow) using capillaries fixed by high-pressure clamps and mixed in the following channel segment. Water is introduced at the makeup flow inlet 3 (cyan). The MS ion path, the liquid beam, and the laser with twelve Osram Oslon SSL royal blue (455 nm) lightemitting diodes (LED, OSRAM GmbH, München, BY, DEU) attached to an aluminum heat sink. The LEDs were operated at $700 \mathrm{~mA}$ per LED.

Chemicals All chemicals were used as received. Caffeine, formic acid, Pirkle's alcohol, hexobarbital, anthracene, and pyrene were purchased from Sigma-Aldrich $\mathrm{GmbH}$ (Taufkirchen, BY, DEU). HPLC grade chloroform $\left(\mathrm{CHCl}_{3}\right.$, purity: $99.8 \%$ ) and $n$-heptane (purity: 97\%) were acquired from VWR International GmbH (Darmstadt, HE, DEU). Photoresist AZ 1518, Developer AZ 351B, and chromium etchant AZ® ECI 3000 were bought from Microchemicals $\mathrm{GmbH}$ (Ulm, BW, DEU). High-purity water was obtained from a Smart2Pure purifying system $(0,055 \mu \mathrm{S} / \mathrm{cm}$, TKA Wasseraufarbeitungssysteme $\mathrm{GmbH}$, Niederelbert, RP, DEU). Starting materials and product of the model reaction $N$-phenyl1,2,3,4-tetrahydroisoquinoline were provided by the Zeitler research group (Institute for Organic Chemistry, Leipzig University, Leipzig, SN, DEU) and synthesized as previously reported [68]. The following solutions were prepared: Pirkle's alcohol, hexobarbital, pyrene in $n$-heptane with the concentrations $0.18 \mathrm{mM}, 0.05 \mathrm{mM}, 5 \mathrm{mM}$, and $5.6 \mathrm{mM}$, respectively. Pyrene, anthracene, $N$-phenyl-1,2,3,4-tetrahydroisoquinoline, and $\mathrm{CBrCl}_{3}$ in $\mathrm{CHCl}_{3}$ have the concentrations $5 \mathrm{mM}$, $5.6 \mathrm{mM}, 1 \mathrm{mM}$, and $1 \mathrm{mM}$ respectively. Caffeine in $\mathrm{CHCl}_{3}$ have concentrations of $1.5,3.0,10,20$, and $50 \mu \mathrm{M}$. Pyrene in $\mathrm{n}$ heptane have concentrations of $0.05,0.25,0.5$, and $1 \mathrm{mM}$.

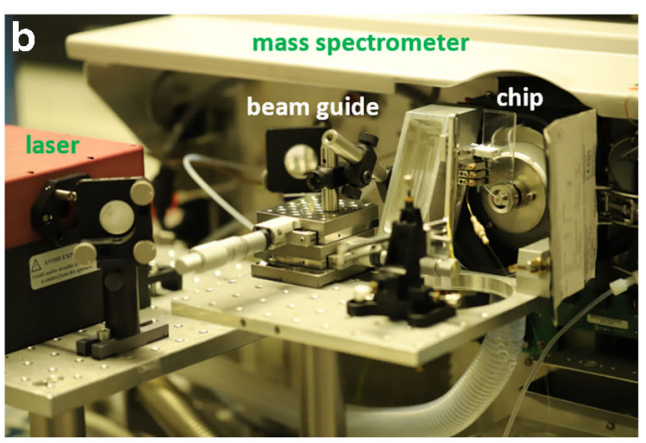

path were each aligned along the $x, y$, and $z$ axes. It is indicated that the liquid jet disperses when hit by the laser, and the droplet cloud moves in laser beam direction due to recoil pressure. $\mathbf{b}$ Image of the setup in front of the mass spectrometer. An in-house built stage positions the chip in front of the mass spectrometer inlet. Mirrors guide the infrared laser beam to a lens that focuses the beam onto the from the chip ejected liquid beam 


\section{Results and discussion}

In initial experiments combining liquid beam IR-MALDI with chip-based droplet microfluidics using water as the continuous phase and water non-miscible solvents as the droplet phase, signals of compounds in the water non-miscible phase were observed unexpectedly. In contrast, no signals were detected without laser irradiation. When solvents without inherent $\mathrm{OH}$ groups are irradiated by a laser beam at the wavelength from 2900 to $3100 \mathrm{~nm}$, basically neither desorption nor ionization of dissolved analytes occurs unless plasma discharge appears. To further investigate this finding, we started a comprehensive study. Microfluidic glass chips with a make-up channel were designed in order to dose water to the nonpolar and non-miscible solvents just before the liquid jet is formed (Fig. 2 inlet 3).

We studied the process by video microscopy to visualize the liquid-phase dispersion process as well as the desorption process when the laser hits the liquid beam (Fig. 3). From literature reports, it is known that different flow patterns can be formed when non-polar phases and water are pumped together in microchannels $[12,66,69,70]$. The outcome of this process is affected by the channel geometries, the ratio of the applied flow rates of the polar and non-polar liquid and the capillary number $C_{\mathrm{a}}=\left(\eta_{\mathrm{c}} v_{\mathrm{c}}\right) / \gamma$, where $\eta_{\mathrm{c}}$ is the viscosity of the continuous phase, $v_{\mathrm{c}}$ the average velocity of the continuous phase, and $\gamma$ the interfacial tension between the continuous and dispersed phases. At a low flow rate ratio, droplets are formed in a carrier flow, whereas at a balanced ratio, a co-flow is formed. The decay of the co-flow into droplets shows a hysteresis behavior depending on the history of the applied phase flow rates [71].

In order to visualize these processes in our setup without blur, where relatively high carrier flow rates (hence flow velocities) are required to generate the liquid jet, a stroboscopic imaging setup was used. In a set of experiments, $n$-heptane was pumped through inlet 1 with different flow rates $\left(u_{1}=1,2,5,10\right.$, and $20 \mu \mathrm{L} / \mathrm{min}$ ) and water was added at inlet 3 as a make-up flow with a flow rate of $u_{3}=120 \mu \mathrm{L} / \mathrm{min}$. Exemplary pictures illustrating this process are depicted in Fig. 3c, d, and e. The images indicate that the liquid jet consists of a stable cylindrical part, which breaks up into a stream of droplets (Rayleigh decay) after a certain length that scales linearly with the flow rate. If $n$-heptane is pumped additionally via inlet 1 , organic solvent droplets appear in the water jet. These form in the microchip channel at low organic solvent flow rates, up to $5 \mu \mathrm{L} / \mathrm{min}$. With an increased organic solvent rate, a co-flow of $n$-heptane and water forms and the break-up to organic droplets within water occur further downstream, and above $10 \mu \mathrm{L} / \mathrm{min}$, it occurs off-chip in the liquid jet. At even higher organic solvent flow rates, the co-flow is stable beyond the collapse of the jet. If this process is now reversed and the flow rate of the organic solvent is reduced, the co-flow remains stable down to flow rates of only $2 \mu \mathrm{L} / \mathrm{min}$. At lower rates, the droplets are again formed in the chip.

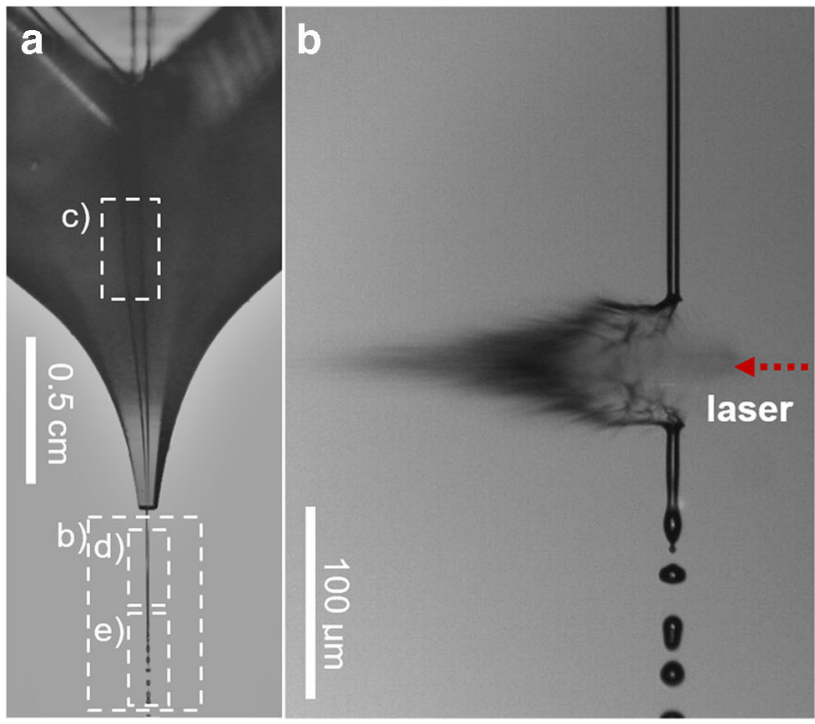

Fig. 3 Stroboscopic images of the two-phase liquid beam in air directly after leaving the chip emitter. a Schematic image of the chip emitting a liquid jet. Rectangles with a dashed border indicate the position of clippings $\mathbf{b}, \mathbf{c}, \mathbf{d}$, and $\mathbf{e}$. In all images the flow rate $\mathrm{u}_{3}$ of water was $120 \mu \mathrm{L} /$ min. b Shows the desorption process $3 \mu$ s after laser impact from the right. It can be seen that the liquid jet receives an impulse (recoil pressure) from evaporating water and is pushed in the direction of the laser beam, with the laser beam indicated in red (objective: $\times 4$ magnification). $\mathbf{c}-\mathbf{e}$ Stroboscopic images displaying the biphasic system consisting of water
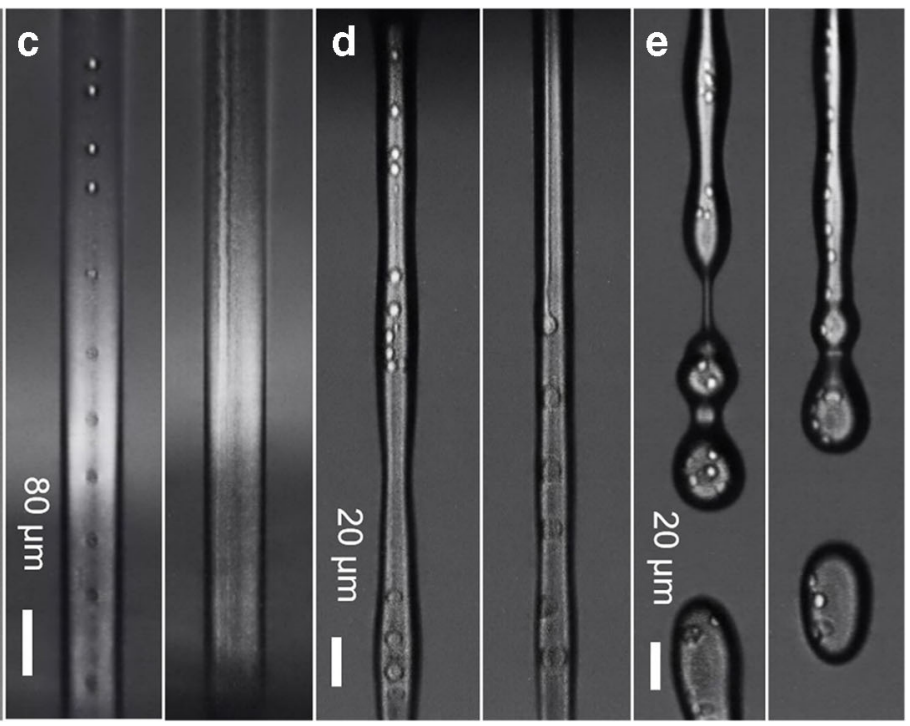

and $n$-heptane still in the chip channel, where the flow rate $u_{1}$ of $n$-heptane was $5 \mu \mathrm{L} / \mathrm{min}$ on the left and $10 \mu \mathrm{L} / \mathrm{min}$ on the right (objective: $\times 20$ magnification). c Liquid beam directly after ejection. d Above $10 \mu \mathrm{L} /$ min, the co-flow decomposition into droplets occurs downstream in the liquid jet. e The liquid jet breaks up into biphasic droplets in air. Images of the desorption process at different times after laser exposure are provided in ESM, Fig. S5. An indication of the scale of the liquid jet, size of laser impact, and size of droplets are provided in the ESM, Figs. S6 to S8 
If such a free-standing liquid water jet with a co-flow or dispersed consecutive non-polar droplets is irradiated with the laser, the jet disperses and the liquid matter partly vaporizes as shown in Fig. 3b. Due to the laser spot size, always several droplets (3-7 droplets) were hit with the laser, as can be abstracted from the images in the ESM (Figs. S6 to S8, pages 89). By comparing stroboscope images at different times after laser excitation, it is possible to determine the time interval in which the liquid jet is completely replaced by new liquid (at $120 \mu \mathrm{L} / \mathrm{min}$ water every $260 \mu \mathrm{s}$ ). If this is extrapolated with the amount of droplets that appear in the beam when $5 \mu \mathrm{L} / \mathrm{min}$ $\mathrm{n}$-heptane is added ( $\sim 10$ droplets), the droplet frequency can be estimated in the order of about $38,000 \mathrm{~Hz}$ (for the calculation, see ESM Figs. S9 to S10, page 10).

To investigate the dispersion and ionization processes for MS compatibility, the microfluidic chip was positioned in front of the entrance orifice of the MS, and an infrared laser beam at $2940 \mathrm{~nm}$ was aligned so that it hits the liquid jet perpendicular to the ion path, as shown in Fig. 2. Solutions of hexobarbital or Pirkle's alcohol in $n$-heptane were pumped via chip inlet 1 at a flow rate $u_{1}=5 \mu \mathrm{L} / \mathrm{min}$. The make-up flow of water occurred at $115 \mu \mathrm{L} / \mathrm{min}$. The resulting ions after laser irradiation were analyzed in negative ion mode. The exposure of the liquid jet to the IR laser immediately resulted in the significant occurrence of analyte ions and corresponding MS data. While hexobarbital gave no signal in positive ion mode,
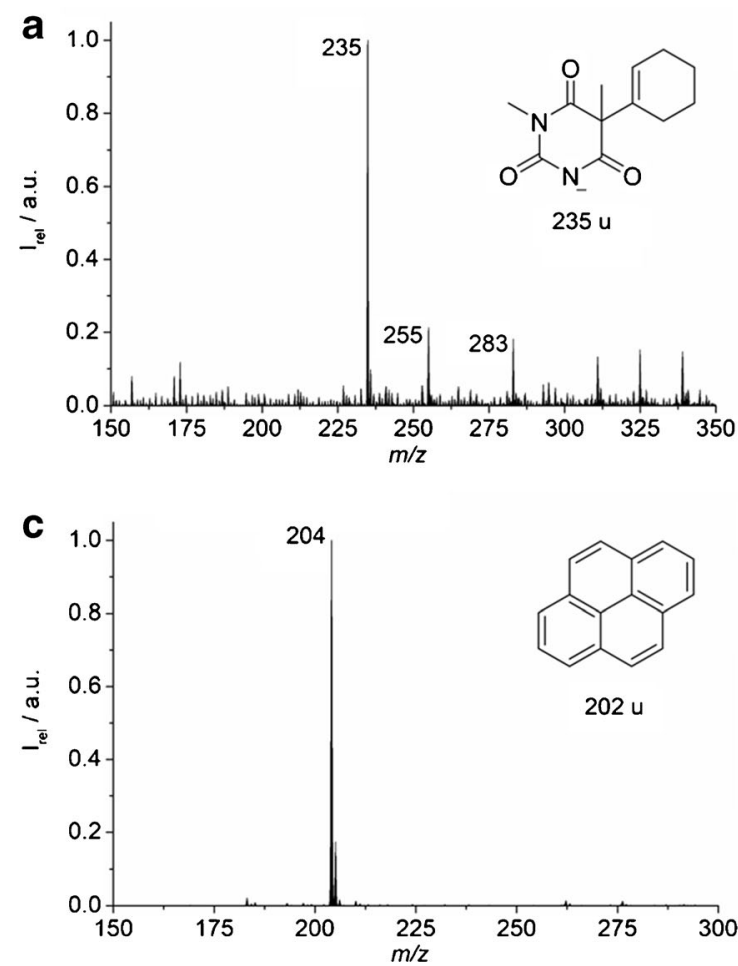

Fig. 4 a Mass spectra of $0.05 \mathrm{mM}$ hexobarbital and b $0.18 \mathrm{mM}$ Pirkle's alcohol in $n$-heptane in negative ion mode. Given sample concentration is the concentration before mixing with the make-up flow. The signals at $m / z, 235$ and 275 correspond to deprotonated anions of the analyte the negative mode mass spectra in Fig. 4 show signals of deprotonated molecules for both compounds. The MS/MS analysis in negative mode of hexobarbital showed no specific product ions. While the experiment was performed at a flow rate ratio where the organic phase in the laser focus is present as droplets in the water jet, the same ions are also observed when irradiating a co-flow liquid jet at a higher organic flow rate. After successfully ionizing these rather polar compounds, we extended these experiments to truly non-polar compounds with very low solubility in the continuous aqueous phase.

For this purpose, the polycyclic aromatic hydrocarbons (PAH) pyrene and anthracene were chosen as model compounds. The compounds were dissolved in $n$-heptane at a concentration of $10 \mathrm{mg} / \mathrm{mL}$ and injected into the chip. As a result, distinctive pyrene and anthracene signals could be obtained. Corresponding mass spectra are depicted in Fig. 4. The base peak for pyrene shows up at $m / z 204\left([\mathrm{M}+2 \mathrm{H}]^{+\bullet}\right)$, and for anthracene, the signal is at $m / z, 180\left([\mathrm{M}+2 \mathrm{H}]^{+\bullet}\right)$. Analogous results were obtained with $\mathrm{CHCl}_{3}$ as the solvent; the corresponding mass spectra are provided in the ESM, Fig. S11. The somewhat unusual quasimolecular ions at $[\mathrm{M}+2 \mathrm{H}]^{+\bullet}$ have also been reported earlier for PAH using low-temperature plasma ionization as another soft ambient ionization technique [72]. It was assumed that both react in a Birch-type reaction, which involved electrons from the ion source, and protons from the silicon surface of the interface. While no radical
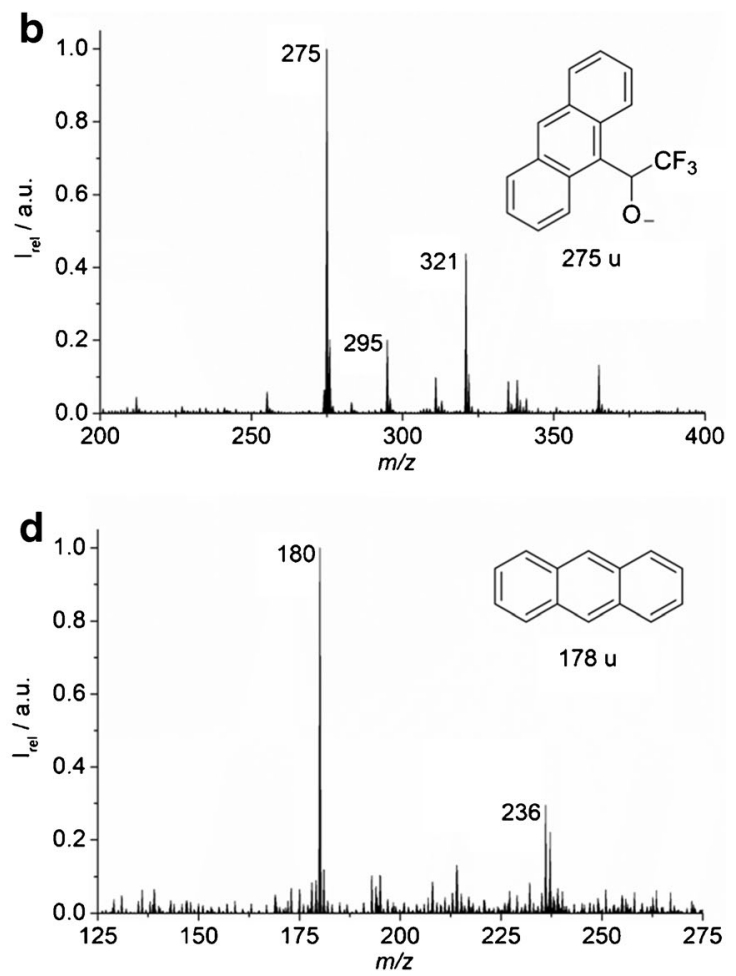

molecules. Spectra of c $5.0 \mathrm{mM}$ pyrene and d $5.6 \mathrm{mM}$ anthracene in $\mathrm{n}$ heptane in positive mode. The signals of both PAHs are from the species $[\mathrm{M}+2 \mathrm{H}]^{+\bullet}$ 

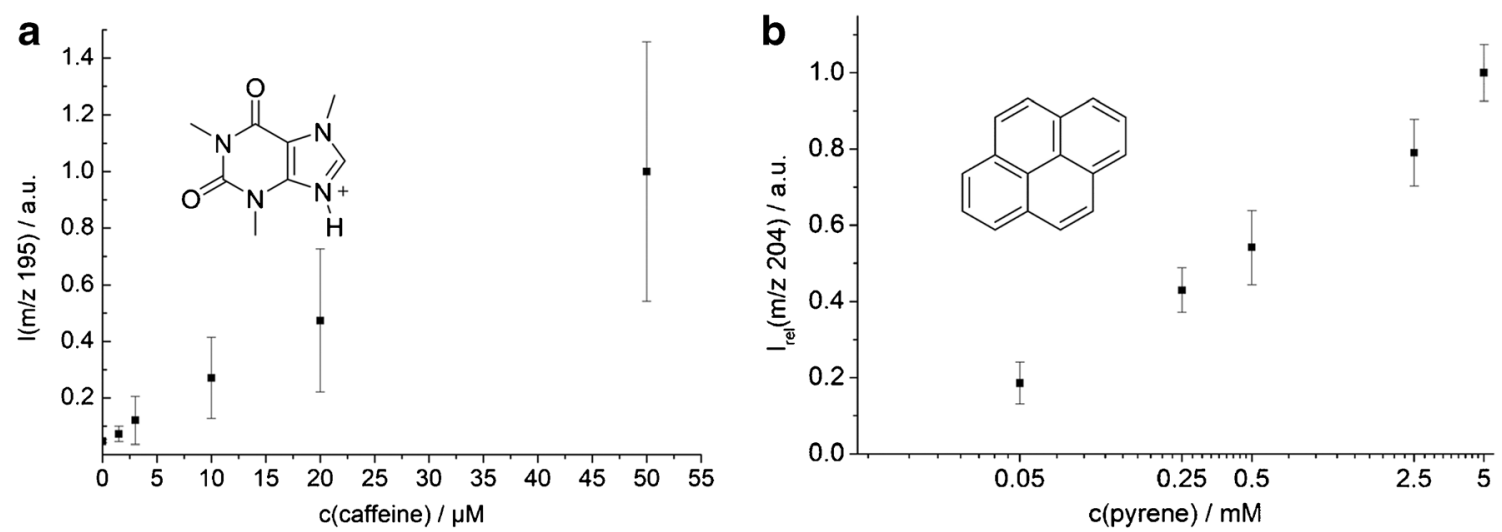

Fig. 5 a Caffeine $0,1.5,3.0,10,20$, and $50 \mu \mathrm{M}$ in $\mathrm{CHCl}_{3}(n=3)$. b Pyrene $0,0.05,0.25,0.5,2.5$, and $5 \mathrm{mM}$ in $n$-heptane $(n=5)$. In both cases, flow rates were $u_{1}=5 \mu \mathrm{L} / \mathrm{min}$ and $u_{3}\left(\mathrm{H}_{2} \mathrm{O}\right)=115 \mu \mathrm{L} / \mathrm{min}$

generation from the interface surface is possible in the IRMALDI setup, quasimolecular ions have been previously reported [73]. Known models for the mechanism of the ionization process are the supercritical phase expansion and incomplete ion recombination model and the liquid dispersion model $[61,74,75]$. In the first, it is assumed that a homogeneously and superheated phase becomes supercritical and expands rapidly after excitation resembling a supersonic hot seeded beam, where cations and anions are generated. Depending on the distance, ions closer to each other will recombine, while those with a larger distance can be isolated. In the second model, it is assumed that the liquid filament is dispersed into nanodroplets with excess charge, which is transferred to contained analytes. Since the signals for PAHs appear at $[\mathrm{M}+2 \mathrm{H}]^{+\bullet}$, the analytes presumably react during the ionization process with the solvent or with each other. As the environment in charged microdroplets differs from that of the bulk, reaction rates are accelerated in charged microdroplets due to extreme $\mathrm{pH}$, an increase of concentration of the reagents, an increased surface area, and increased collision frequencies [76, 77]. In our case, two possible hydrogen and electron donors are plausible: donation from another analyte molecule, or from the solvent, i.e., n-heptane, $\mathrm{CHCl}_{3}$, or water.

These preliminary experiments were conducted at relatively high analyte concentrations in $n$-heptane or $\mathrm{CHCl}_{3}$, as the matrix "dilutes" the sample depending on flow rates. While these concentrations fit well to typical substrate concentrations in a continuous flow synthesis, the lower concentrations are also worth being investigated. For this purpose, a concentration series of caffeine in $\mathrm{CHCl}_{3}$ was measured. The results of the measurement are shown in Fig. 5. The signal of the protonated caffeine scales linearly with the concentration up to about $50 \mu \mathrm{M}$. Beyond that, deviation from the linearity starts due to a saturation effect (ESM, Figs. S12 to S13, page 12). A limit of detection of $4.2 \mu \mathrm{M}$ was determined for this system by linear regression. While certain additives such as formic acid, bases and salts can enhance signals, this depends on the analyte. With caffeine, no significant increase in signal intensity was observed with the addition of formic acid.

The ionization mechanism is still a topic of current research [63]. It would be conceivable that the substances diffuse to some extent from the solvent into the water matrix and are then ionized there. In this case, the signal response of a chemical would hardly increase beyond its solubility in water. To test this, a concentration series of pyrene in $n$-heptane was measured. The solubility of pyrene in $n$-heptane is $12 \mathrm{mM}$, whereby it dissolves in water only up to a concentration of $0.66 \mu \mathrm{M}[78,79]$. As depicted in Fig. 5, the experiment showed that the signal increases up to a concentration of $5 \mu \mathrm{M}$. A comparative measurement was carried out, in which a saturated aqueous pyrene solution was examined. This solution was pumped directly with a high flow rate without adding further water matrix. Therefore, it was not diluted by make-up flow in comparison to the $n$-heptane solutions. In this measurement, the signal of pyrene was hardly distinguishable from noise (ESM, Fig. S11c, page 11). These experiments indicate that most of the pyrene gets ionized directly out of the non-polar phase during the ablation process.

After this first successful realization of on-chip MS detection in water non-miscible solvents, we tested the applicability

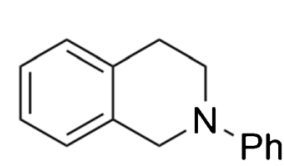

1

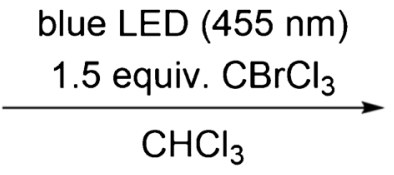

$10 \mathrm{~min}$ in batch synthesis

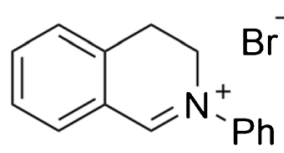

3

Scheme 1 Investigated model reaction: photooxidation of $N$-phenyl-1,2,3,4-tetrahydroisoquinoline (1) with $\mathrm{CBrCl}_{3}(\mathbf{2})$ to $N$-phenyl-3,4dihydroisoquinolium bromide (3) in $\mathrm{CHCl}_{3}$ 

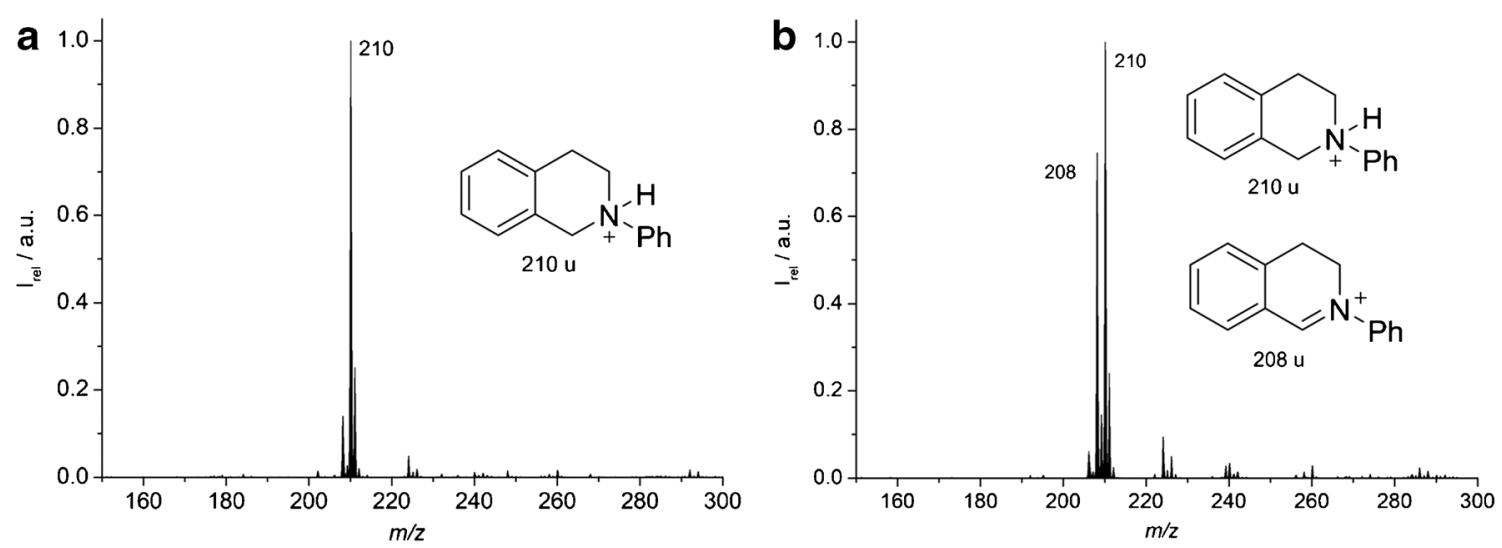

Fig. 6 a Mass spectrum of 1. b Progress of the $N$-phenyl-1,2,3,4-tetrahydroisoquinoline photooxidation on chip in $\mathrm{CHCl}_{3}$ after 16-s residence time, with the corresponding ions of $\mathbf{1}$ at $\mathrm{m} / \mathrm{z}, 210$ and of $\mathbf{3}$ at $\mathrm{m} / \mathrm{z}, 208$

of this technology for the online analysis of a photochemical organic on-chip reaction. As a proof of concept study, we chose the photooxidation of $N$-phenyl-1,2,3,4tetrahydroisoquinoline (1) (Scheme 1). It is known that the iminium ion $N$-phenyl-3,4-dihydroisoquinolium ion (3) can be produced from the tertiary amines tetrahydroisoquinoline by using metal- and photo-catalysis with, e.g., air, oxygen, or $\mathrm{CBrCl}_{3}$ as sacrificial electron acceptors [80-82]. Zeitler et al. described that the reaction can be performed with $\mathrm{CBrCl}_{3}$ without the use of photocatalysts. These conditions transform isoquinoline $\mathbf{1}$ to the corresponding iminium ion $\mathbf{3}$, while avoiding detrimental interactions with reactive oxygen intermediates [68]. The reaction is known to be very fast, and in batch, a full turnover is reached within minutes.

To study this reaction on-chip, starting material 1 was dissolved in $\mathrm{CHCl}_{3} 1.0 \mathrm{mM}$ and pumped at a volume flow rate of $1 \mu \mathrm{L} / \mathrm{min}$ through inlet 1 (NMR spectra for starting materials: ESM, Figs. S14 to S15, pages 14-15). At the end of the reaction channel, water was supplied through inlet 3 at a flow rate of $120 \mu \mathrm{L} / \mathrm{min}$. The acquired mass spectra of $\mathbf{1}$ is displayed in Fig. 6a. To start the reaction, $1 \mathrm{mM}$ solution of $\mathrm{CBrCl}_{3}(2)$ in $\mathrm{CHCl}_{3}$ was added at $1 \mu \mathrm{L} / \mathrm{min}$ via inlet 2 . This corresponded to a residence time of $16 \mathrm{~s}$ of both liquids in the reaction region of the chip (ESM, page 4). To initiate the photoreaction, the chip was illuminated by a blue LED with a wavelength of $455 \mathrm{~nm}$. After adding the solution of compound $\mathbf{2}$, the resulting mass spectrum (Fig. 6b) displays the signal at $m / z 208$, which can be assigned to the product of the reaction (iminium ion) 3 . These proof of concept experiments indicate that the presented liquid beam infrared MALDI approach is suitable to monitor a microflow synthesis on-chip occurring in organic solvents.

One limitation of the current setup is that it provides a relatively low signal intensity compared to electrospray ionization. The reasons for this are that the sample is strongly diluted with the aqueous matrix to produce a liquid jet and that only a fraction of the sample is covered by the slow laser frequency. Future work is planned to address these technical aspects more thoroughly, in order to improve the signal intensity.

\section{Conclusion}

In this work, we showed the first example of studying chemical processes in water non-miscible solvents on-chip applying IR-MALDI. We used a microfluidic glass chip with a fine pulled emitter tip to generate a stable aqueous jet that contained droplets of chloroform or $n$-heptane. Water hereby acted as a matrix that absorbs IR laser light, inducing desorption and ionization of dissolved analytes in the organic liquid. The technique was used to monitor a transformation of $\mathrm{N}$ phenyl-1,2,3,4-tetrahydroisoquinoline in chloroform. With this approach, it is now possible for the first time to follow on-chip reactions in non-polar and water non-miscible organic solvents by mass spectrometry, with correspondingly versatile potential, not only for flow chemistry applications.

Supplementary Information The online version contains supplementary material available at https://doi.org/10.1007/s00216-020-03115-4 .

Funding Open Access funding enabled and organized by Projekt DEAL. This work was funded by the Deutsche Forschungsgemeinschaft (DFG) within the framework of the research unit FOR 2177 ("Integrated Chemical Micro Laboratories") project number BE 1922/13-2, AB 63/ 16-2, and ZE 717/7-1.

\section{Compliance with ethical standards}

Conflict of interest The authors declare that there are no conflicts of interest.

Open Access This article is licensed under a Creative Commons Attribution 4.0 International License, which permits use, sharing, adaptation, distribution and reproduction in any medium or format, as long as you give appropriate credit to the original author(s) and the source, provide a link to the Creative Commons licence, and indicate if changes were made. The images or other third party material in this article are included in the article's Creative Commons licence, unless indicated otherwise in a credit line to the material. If material is not included in the article's Creative Commons licence and your intended use is not permitted by statutory regulation or exceeds the permitted use, you will need to obtain permission directly from the copyright holder. To view a copy of this licence, visit http://creativecommons.org/licenses/by/4.0/. 


\section{References}

1. Feng X, Liu B-F, Li J, Liu X. Advances in coupling microfluidic chips to mass spectrometry. Mass Spectrom Rev. 2015;34:535-57.

2. Wang X, Yi L, Mukhitov N, Schrell AM, Dhumpa R, Roper MG. Microfluidics-to-mass spectrometry: a review of coupling methods and applications. J Chromatogr A. 2015;1382:98-116.

3. Oedit A, Vulto P, Ramautar R, Lindenburg PW, Hankemeier T. Lab-on-a-Chip hyphenation with mass spectrometry: strategies for bioanalytical applications. Curr Opin Biotechnol. 2015;31:79-85.

4. Mao S, Li W, Zhang Q, Zhang W, Huang Q, Lin J-M. Cell analysis on chip-mass spectrometry. Trends Anal Chem. 2018;107:43-59.

5. Scholl T, Dietze C, Schmidt M, Ohla S, Belder D. Sheathless coupling of microchip electrophoresis to ESI-MS utilising an integrated photo polymerised membrane for electric contacting. Anal Bioanal Chem. 2018;410:5741-50.

6. Redman EA, Ramos-Payan M, Mellors JS, Ramsey JM. Analysis of hemoglobin glycation using microfluidic CE-MS: a rapid, mass spectrometry compatible method for assessing diabetes management. Anal Chem. 2016;88:5324-30.

7. Deng Y, Qiao L, Gasilova N, Zhang X-X, Girault HH. Open channel-based microchip electrophoresis interfaced with mass spectrometry via electrostatic spray ionization. Chin Chem Lett. 2016;27:85-7.

8. Piendl SK, Geissler D, Weigelt L, Belder D. Multiple heart-cutting two-dimensional chip-HPLC combined with deep-UV fluorescence and mass spectrometric detection. Anal Chem. 2020;92:3795-803.

9. Pereira F, Niu X, deMello AJ. A nano LC-MALDI mass spectrometry droplet interface for the analysis of complex protein samples. PLoS One. 2013;8:e63087.

10. Chambers AG, Mellors JS, Henley WH, Ramsey JM. Monolithic integration of two-dimensional liquid chromatography-capillary electrophoresis and electrospray ionization on a microfluidic device. Anal Chem. 2011;83:842-9.

11. Warias R, Zaghi A, Heiland JJ, Piendl SK, Gilmore K, Seeberger $\mathrm{PH}$, et al. An integrated lab-on-a-chip approach to study heterogeneous enantioselective catalysts at the microscale. ChemCatChem. 2018;10:5382-5.

12. Beulig RJ, Warias R, Heiland JJ, Ohla S, Zeitler K, Belder D. A droplet-chip/mass spectrometry approach to study organic synthesis at nanoliter scale. Lab Chip. 2017;17:1996-2002.

13. Prudent M, Rossier JS, Lion N, Girault HH. Microfabricated dual sprayer for on-line mass tagging of phosphopeptides. Anal Chem. 2008;80:2531-8

14. deMello AJ. Control and detection of chemical reactions in microfluidic systems. Nature. 2006;442:394-402.

15. Wink K, Mahler L, Beulig JR, Piendl SK, Roth M, Belder D. An integrated chip-mass spectrometry and epifluorescence approach for online monitoring of bioactive metabolites from incubated Actinobacteria in picoliter droplets. Anal Bioanal Chem. 2018;410:7679-87.

16. Fidalgo LM, Whyte G, Ruotolo BT, Benesch JLP, Stengel F, Abell $\mathrm{C}$, et al. Coupling microdroplet microreactors with mass spectrometry: reading the contents of single droplets online. Angew Chem Int Ed Eng. 2009;48:3665-8.

17. Gasilova N, Yu Q, Qiao L, Girault HH. On-chip spyhole mass spectrometry for droplet-based microfluidics. Angew Chem Int Ed Eng. 2014;53:4408-12.

18. Huang C-M, Zhu Y, Jin D-Q, Kelly RT, Fang Q. Direct surface and droplet microsampling for electrospray ionization mass spectrometry analysis with an integrated dual-probe microfluidic chip. Anal Chem. 2017;89:9009-16.

19. Sun S, Kennedy RT. Droplet electrospray ionization mass spectrometry for high throughput screening for enzyme inhibitors. Anal Chem. 2014;86:9309-14.
20. Liu C, Choi K, Kang Y, Kim J, Fobel C, Seale B, et al. Direct interface between digital microfluidics and high performance liquid chromatography-mass spectrometry. Anal Chem. 2015;87:1196772 .

21. Kirby AE, Wheeler AR. Microfluidic origami: a new device format for in-line reaction monitoring by nanoelectrospray ionization mass spectrometry. Lab Chip. 2013;13:2533-40.

22. Baker CA, Roper MG. Online coupling of digital microfluidic devices with mass spectrometry detection using an eductor with electrospray ionization. Anal Chem. 2012;84:2955-60.

23. Chen S, Wan Q, Badu-Tawiah AK. Mass spectrometry for paperbased immunoassays: toward on-demand diagnosis. J Am Chem Soc. 2016;138:6356-9.

24. Liu W, Lin J-M. Online monitoring of lactate efflux by multichannel microfluidic chip-mass spectrometry for rapid drug evaluation. ACS Sens. 2016;1:344-7.

25. Manicke NE, Bills BJ, Zhang C. Analysis of biofluids by paper spray MS: advances and challenges. Bioanalysis. 2016;8:589-606.

26. McKenna J, Dhummakupt ES, Connell T, Demond PS, Miller DB, Michael Nilles J, et al. Detection of chemical warfare agent simulants and hydrolysis products in biological samples by paper spray mass spectrometry. Analyst. 2017;142:1442-51.

27. Ingram AJ, Boeser CL, Zare RN. Going beyond electrospray: mass spectrometric studies of chemical reactions in and on liquids. Chem Sci. 2016;7:39-55.

28. Herrera LC, Grossert JS, Ramaley L. Quantitative aspects of and ionization mechanisms in positive-ion atmospheric pressure chemical ionization mass spectrometry. J Am Soc Mass Spectrom. 2008; 19:1926-41.

29. Hourani N, Muller H, Adam FM, Panda SK, Witt M, Al-Hajji AA, et al. Structural level characterization of base oils using advanced analytical techniques. Energy Fuel. 2015;29:2962-70.

30. Jin C, Viidanoja J, Li M, Zhang Y, Ikonen E, Root A, et al. Comparison of atmospheric pressure chemical ionization and field ionization mass spectrometry for the analysis of large saturated hydrocarbons. Anal Chem. 2016;88:10592-8.

31. Ostman P, Jäntti S, Grigoras K, Saarela V, Ketola RA, Franssila S, et al. Capillary liquid chromatography-microchip atmospheric pressure chemical ionization-mass spectrometry. Lab Chip. 2006;6: 948-53.

32. Zhang J-T, Wang H-Y, Zhu W, Cai T-T, Guo Y-L. Solvent-assisted electrospray ionization for direct analysis of various compounds (complex) from low/nonpolar solvents and eluents. Anal Chem. 2014;86:8937-42.

33. Elmongy H, Ahmed H, Wahbi A-A, Koyi H, Abdel-Rehim M. Online post-column solvent assisted and direct solvent-assisted electrospray ionization for chiral analysis of propranolol enantiomers in plasma samples. J Chromatogr A. 2015;1418:110-8.

34. Zhang Q, Su Y, Liu X, Guo Y. Rapid characterization of nonpolar or low-polarity solvent extracts from herbal medicines by solventassisted electrospray ionization mass spectrometry. Rapid Commun Mass Spectrom. 2018;32:221-9.

35. Mark LP, Gill MC, Mahut M, Derrick PJ. Dual nano-electrospray for probing solution interactions and fast reactions of complex biomolecules. Eur J Mass Spectrom (Chichester). 2012;18:439-46.

36. Sen AK, Darabi J, Knapp DR. Design, fabrication and test of a microfluidic nebulizer chip for desorption electrospray ionization mass spectrometry. Sensors Actuators B Chem. 2009;137:789-96.

37. Li X, Yin R, Hu H, Li Y, Sun X, Dey SK, et al. An integrated microfluidic probe for mass spectrometry imaging of biological samples. Angew Chem. 2020;132:1-5.

38. Li X, Xu R, Wei X, Hu H, Zhao S, Liu Y-M. Direct analysis of biofluids by mass spectrometry with microfluidic voltage-assisted liquid desorption electrospray ionization. Anal Chem. 2017;89: 12014-22. 
39. Cotte-Rodríguez I, Takáts Z, Talaty N, Chen H, Cooks RG. Desorption electrospray ionization of explosives on surfaces: sensitivity and selectivity enhancement by reactive desorption electrospray ionization. Anal Chem. 2005;77:6755-64.

40. Chung K, Banik SM, de Crisci AG, Pearson DM, Blake TR, Olsson $\mathrm{JV}$, et al. Chemoselective Pd-catalyzed oxidation of polyols: synthetic scope and mechanistic studies. J Am Chem Soc. 2013;135: 7593-602.

41. Santos VG, Regiani T, Dias FFG, Romão W, Jara JLP, Klitzke CF, et al. Venturi easy ambient sonic-spray ionization. Anal Chem. 2011;83:1375-80.

42. Jjunju FPM, Maher S, Li A, Badu-Tawiah AK, Taylor S, Graham $\mathrm{CR}$. Analysis of polycyclic aromatic hydrocarbons using desorption atmospheric pressure chemical ionization coupled to a portable mass spectrometer. J Am Soc Mass Spectrom. 2015;26:271-80.

43. Yu C, Qian X, Chen Y, Yu Q, Ni K, Wang X. Microfluidic selfaspiration sonic-spray ionization chip with single and dual ionization channels for mass spectrometry. RSC Adv. 2016;6:50180-9.

44. van Geenen FAMG, Franssen MCR, Zuilhof H, Nielen MWF. Reactive laser ablation electrospray ionization time-resolved mass spectrometry of click reactions. Anal Chem. 2018;90:10409-16.

45. Ma X, Zhang S, Lin Z, Liu Y, Xing Z, Yang C, et al. Real-time monitoring of chemical reactions by mass spectrometry utilizing a low-temperature plasma probe. Analyst. 2009;134:1863-7.

46. Macha SF, Limbach PA, Savickas PJ. Application of nonpolar matrices for the analysis of low molecular weight nonpolar synthetic polymers by matrix-assisted laser desorption/ionization time-offlight mass spectrometry. J Am Soc Mass Spectrom. 2000;11:7317.

47. Robins $\mathrm{C}$, Limbach PA. The use of nonpolar matrices for matrixassisted laser desorption/ionization mass spectrometric analysis of high boiling crude oil fractions. Rapid Commun Mass Spectrom. 2003; 17:2839-45.

48. Weidner S, Kühn G, Friedrich J. Infrared-matrix-assisted laser desorption/ionization and infrared-laser desorption/ionization investigations of synthetic polymers. Rapid Commun Mass Spectrom. 1998;12:1373-81.

49. Küster SK, Pabst M, Jefimovs K, Zenobi R, Dittrich PS. Highresolution droplet-based fractionation of nano-LC separations onto microarrays for MALDI-MS analysis. Anal Chem. 2014;86:484855 .

50. Schulze S, Pahl M, Stolz F, Appun J, Abel B, Schneider C, et al. Liquid beam desorption mass spectrometry for the investigation of continuous flow reactions in microfluidic chips. Anal Chem. 2017;89:6175-81.

51. Kleinekofort W, Avdiev J, Brutschy B. A new method of laser desorption mass spectrometry for the study of biological macromolecules. Int J Mass Spectrom Ion Process. 1996;152:135-42.

52. Michalik-Onichimowska A, Beitz T, Panne U, Löhmannsröben HG, Riedel J. Microsecond mid-infrared laser pulses for atmospheric pressure laser ablation/ionization of liquid samples. Sensors Actuators B Chem. 2017;238:298-305.

53. Villatoro J, Zühlke M, Riebe D, Beitz T, Weber M, Riedel J, et al. IR-MALDI ion mobility spectrometry: physical source characterization and application as HPLC detector. Int J Ion Mobil Spectrom. 2016;19:197-207.

54. Sobott F, Wattenberg A, Kleinekofort W, Pfenninger A, Brutschy B. Laser desorption mass spectrometry on thin liquid jets. Fresenius J Anal Chem. 1998;360:745-9.

55. Wattenberg A, Sobott F, Barth H-D, Brutschy B. Laser desorption mass spectrometry on liquid beams. Eur J Mass Spectrom. 1999;5: $71-6$.

56. Huang F, Murray KK. Continuous flow infrared matrix-assisted laser desorption electrospray ionization mass spectrometry. Rapid Commun Mass Spectrom. 2010;24:2799-804.
57. Postberg F, Khawaja N, Abel B, Choblet G, Glein CR, Gudipati MS, et al. Macromolecular organic compounds from the depths of Enceladus. Nature. 2018;558:564-8.

58. Peetz O, Hellwig N, Henrich E, Mezhyrova J, Dötsch V, Bernhard F, et al. LILBID and nESI: different native mass spectrometry techniques as tools in structural biology. J Am Soc Mass Spectrom. 2019;30:181-91.

59. Faubel M, Schlemmer S, Toennies JP. A molecular beam study of the evaporation of water from a liquid jet. Z Phys D Atom $\mathrm{Mol} \mathrm{Cl}$. 1988;10:269-77.

60. Gladytz T, Abel B, Siefermann KR. Expansion dynamics of supercritical water probed by picosecond time-resolved photoelectron spectroscopy. Phys Chem Chem Phys. 2015;17:4926-36.

61. Wiederschein F, Vohringer-Martinez E, Beinsen A, Postberg F, Schmidt J, Srama R, et al. Charge separation and isolation in strong water droplet impacts. Phys Chem Chem Phys. 2015;17:6858-64.

62. Rapp E, Charvat A, Beinsen A, Plessmann U, Reichl U, SeidelMorgenstern A, et al. Atmospheric pressure free liquid infrared MALDI mass spectrometry: toward a combined ESI/ MALDIliquid chromatography interface. Anal Chem. 2009;81:443-52.

63. Fatou B, Ziskind M, Saudemont P, Quanico J, Focsa C, Salzet M, et al. Remote atmospheric pressure infrared matrix-assisted laser desorption-ionization mass spectrometry (remote IR-MALDI MS) of proteins. Mol Cell Proteomics. 2018;17:1637-49.

64. Stolz F, Appun J, Naumov S, Schneider C, Abel B. A complex catalytic reaction caught in the act: intermediates and products sampling online by liquid $\mu$-beam mass spectrometry and theoretical modeling. ChemPlusChem. 2017;82:233-40.

65. Lotter C, Heiland JJ, Stein V, Klimkait M, Queisser M, Belder D. Evaluation of pressure stable Chip-to-tube fittings enabling highspeed chip-HPLC with mass spectrometric detection. Anal Chem. 2016;88:7481-6.

66. Gerhardt RF, Peretzki AJ, Piendl SK, Belder D. Seamless combination of high-pressure chip-HPLC and droplet microfluidics on an integrated microfluidic glass chip. Anal Chem. 2017;89:13030-7.

67. Lotter C, Heiland JJ, Thurmann S, Mauritz L, Belder D. HPLC-MS with glass chips featuring monolithically integrated electrospray emitters of different geometries. Anal Chem. 2016;88:2856-63.

68. Franz JF, Kraus WB, Zeitler K. No photocatalyst required-versatile, visible light mediated transformations with polyhalomethanes. Chem Commun (Camb). 2015;51:8280-3.

69. Dendukuri D, Tsoi K, Hatton TA, Doyle PS. Controlled synthesis of nonspherical microparticles using microfluidics. Langmuir. 2005;21:2113-6.

70. Nisisako T, Torii T, Higuchi T. Novel microreactors for functional polymer beads. Chem Eng J. 2004;101:23-9.

71. Zagnoni M, Anderson J, Cooper JM. Hysteresis in multiphase microfluidics at a T-junction. Langmuir. 2010;26:9416-22.

72. Na N, Xia Y, Zhu Z, Zhang X, Cooks RG. Birch reduction of benzene in a low-temperature plasma. Angew Chem Int Ed Eng. 2009;48:2017-9.

73. Dreisewerd K, Berkenkamp S, Leisner A, Rohlfing A, Menzel C. Fundamentals of matrix-assisted laser desorption/ionization mass spectrometry with pulsed infrared lasers. Int J Mass Spectrom. 2003;226:189-209.

74. Charvat A, Abel B. How to make big molecules fly out of liquid water: applications, features and physics of laser assisted liquid phase dispersion mass spectrometry. Phys Chem Chem Phys. 2007;9:3335-60.

75. Karas M, Hillenkamp F. Laser desorption ionization of proteins with molecular masses exceeding 10,000 daltons. Anal Chem. 1988;60:2299-301.

76. Banerjee S, Zare RN. Syntheses of Isoquinoline and substituted Quinolines in charged microdroplets. Angew Chem. 2015;127: 15008-12. 
77. Girod M, Moyano E, Campbell DI, Cooks RG. Accelerated bimolecular reactions in microdroplets studied by desorption electrospray ionization mass spectrometry. Chem Sci. 2011;2: 501-10.

78. Burgess D. IUPAC/NIST solubility data series, NIST standard reference database 106. 2007. https://srdata.nist.gov/solubility/sol_ detail.aspx?sysID=38 374. Accessed July 2020.

79. Burgess D. IUPAC/NIST Solubility Data Series, NIST Standard Reference Database 106. 2007. https://srdata.nist.gov/solubility/ sol_detail.aspx?sysID=59_402. Accessed July 2020.

80. Freeman DB, Furst L, Condie AG, Stephenson CRJ. Functionally diverse nucleophilic trapping of iminium intermediates generated utilizing visible light. Org Lett. 2012;14:94-7.
81. Liu Q, Li Y-N, Zhang H-H, Chen B, Tung C-H, Wu L-Z. Reactivity and mechanistic insight into visible-light-induced aerobic crossdehydrogenative coupling reaction by organophotocatalysts. Chemistry. 2012;18:620-7.

82. Bartling H, Eisenhofer A, König B, Gschwind RM. The photocatalyzed Aza-Henry reaction of $\mathrm{N}$-aryltetrahydroisoquinolines: comprehensive mechanism, $\mathrm{H} \cdot-$ versus $\mathrm{H}+$-abstraction, and background reactions. J Am Chem Soc. 2016;138:11860-71.

Publisher's note Springer Nature remains neutral with regard to jurisdictional claims in published maps and institutional affiliations. 